\title{
A obesidade como objeto complexo: uma abordagem filosófico-conceitual
}

\author{
O besity as a complex object: \\ a philosophical and conceptual approach
}

Maria Cláudia Carvalho 1

André M artins 2

\footnotetext{
1 Instituto de Nutrição daUERJ.

Rua Pinheiro Guimarães

115/407 bloco II, 22280-080,

Rio de Janeiro RJ.

mariaclaudia@rio.skydome

.com.br

2 Núcleo de Estudos em

Saúde Coletiva (NESC),

UFRJ.
}

\begin{abstract}
This article looks into the construction of concepts in the health area and their use as a methodological instrument in the dissolution of limiting dichotomies such as the one between body and mind. This work starts from a philosophical perspective, in the attempt to look closer into the complex reality of collective health, applied to the problems related to obesity. We discuss how to overcome opposing issues such as "to eat because I want and not to eat because it makes me fat", understanding the eating conflicts and the nutritional aggravations from an ethical point-of-view, so as to bring together theory and practice within contemporaneity. To exercise this conceptualization, we have formulated two definitions of obesity: first, taking into account the singular capacity of each individual to be active and powerful in life; second, considering the current standards of normality for the human bodies. To sum up, we describe some possible uses of this instrument in the areas of nutrition and health, so as to prevent the reduction of human beings to halves, body or soul, and to understand them in their integrality.
\end{abstract}

Key words 0 besity, Conceptualization in health, Philosophy, Complexity
Resumo 0 artigo examina a construção de conceitos na área da saúde e sua utilização como um instrumento metodológico na dissolução de dicotomias limitantes como a de corpo/mente. 0 trabalho parte de uma perspectiva da filosofia em busca de uma aproximação com a realidade complexa da saúde coletiva, aplicada à problemática da obesidade. Discute a superação de oposições como a do "comer porque quero e não comer porque engorda" numa compreensão ética dos conflitos alimentares e agravos nutricionais, de modo a articular teoria e prática na contemporaneidade. Foram elaboradas, como exercício de conceituação, duas definições de obesidade. U ma levando em conta a capacidade singular de as pessoas estarem ativas e potentes na vida, e outra considerando os padrões atuais de normalidade para os corpos. Concluímos descrevendo al gumas possibilidades de utilização desse recurso na área de alimentação e saúde de forma que o ser humano não seja reduzido a uma metade, seja ela corpo ou alma, mas que seja compreendido em sua integralidade.

Palavras-chave 0 besidade, Conceituação em saúde, Ética, Filosofia, Complexidade 


\section{Introdução}

Neste início do século 21, a saúde coletiva enfrenta uma questionável, senão falsa, oposição entre obesidade e desnutrição na transição epidemiológica que ocorre no Brasil. Uma observação apressada pode reduzir a diversidade de uma questão alimentar a uma simples oposição entre desnutrição/obesidade, criando dicotomias como a associação de desnutrição à baixa renda e de obesidade ao seu oposto, assim como da obesidade a um alto valor energético da dieta e da desnutrição a uma dieta de baixo valor energético. No entanto, como observa M onteiro (2000), a obesidade também está associada à baixa renda, mostrando que o universo dos agravos nutricionais é complexo. Da mesma forma, também é complexa a construção dos sentidos atribuídos a esses agravos em nossa cultura contemporânea. E esses sentidos atribuídos influem decisivamente nos próprios agravos.

0 ato de se alimentar constitui-se na dimensão ampla do humano enão se limita a um aspecto mecânico e mensurável. A compreensão do perfil nutricional da população não pode se reduzir, por conseguinte, a variáveis antropométricas. O besidade não representa uma simples questão de balanço energético positivo (M onteiro, 2001). A definição de obesidade como um balanço energético tem uma orientação determinista, que traria em si como solução ingerir menos ou gastar mais energia. Entretanto, o aumento progressivo da prevalência de obesidade na população impõe uma reflexão, além dessa orientação. A objetividade e o pragmatismo da modernidade trouxeram al gumas possibilidades de se modelar corpos com cirurgias, implantes ou anabolizantes, em formas e estilos diversos. Isto tende a nos distanciar de nossa capacidade criativa, humana e singular, na medida em que submete a mobilidade da vida a formas estáticas como a de uma estampa de revista.

Partindo de uma perspectiva da filosofia, buscamos reconstruir uma concepção de corpo capaz de incluir suas inter-relações com 0 ambiente no sentido de absorver a complexidade da alimentação humana. 0 corpo gordo não é como uma máquina mensurável que ingere e excreta substâncias independente do ambiente. 0 corpo é parte do ambiente em que vive e, como tal, se apropria do ambiente a cada momento, interagindo e modificando os processos de transdução de energia. A concei- tuação de obesi dade se coloca justamente nessa inter-relação e, desse modo, é preciso debruçar o olhar sobre o próprio conhecimento, sobre nossa forma de construir conceitos, para meIhor entendermos o que está em jogo na construção do conceito de obesidade no que ele traz dessas dicotomias hegemônicas.

0 mecanicismo que aposta em relações lineares de causa e efeito está destinado a fazer de um conceito somente uma definição, sem ação transformadora na práxis. 0 paradigma clássico-moderno, com sua estrutura determinista e mecanicista, não se constitui um instrumental teórico-conceitual capaz de enfrentar a complexidade intrínseca ao campo da saúde coletiva. Quando se baseia numa representatividade numérica e esvaziada de sentidos (supostamente neutra), não permite um aprofundamento nos significados e sentidos que constituem as várias facetas de um objeto complexo. M as se, por um lado, o paradigma clássicomoderno não é suficiente como fundamentação teórica para a complexidade, por outro, é preciso ainda definir os fundamentos teóricos capazes de superar as dicotomias clássicas corpo/mente, quantitativo/qualitativo, sem que isso represente uma forma de transcender à realidade, mas uma forma de alargar as possibilidades de transformação inerentes ao ser humano eà esfera do social.

Nesse sentido, entendemos como fundamental a necessidade de construir referências teóricas que permitam uma abordagem e uma compreensão dos fenômenos complexos, explicitando ejustificando estas escol has e os respectivos pressupostos conceituais. U ma metodologia que tenha por base a natureza complexa de qualquer objeto de estudo, sobretudo na área da saúde, deve buscar compreender, comparar, analisar e descrever seus pressupostos conceituais. A conceituação, em nosso método de investigação, representa uma possibilidade de flexibilizar definições usuais, até então estáticas, a fim de transpor as barreiras formais da disciplinarização moderna, articulando a teoria, e sua fundamentação, com sua utilização, através da construção de conceitos operacionais. Um conceito pode ser retirado de um corpo filosófico do século 17, como o de Espinosa, por exemplo, para ser operacionalizado de forma atual, pois nenhum conceito traz em si a exigência de ser sempre o mesmo (Deleuze, 1991), bastando que explicitemos o modo como o estamos entendendo, de maneira a torná-lo operacional no contexto em que estará sendo utilizado. 


\section{Um ponto de partida: a filosofia de Espinosa}

Para a conceituação de nosso objeto partimos da contraposição de duas racionalidades diferentes estabelecidas por dois pensadores do século 17, Descartes e Espinosa. Os princípios do cartesianismo inauguraram o determinismo clássico-formal. As verdades cartesianas, visando constituir leis universais, representam as raízes da ciência moderna como nós a conhecemos na área da saúde - em particular, na medicina moderna que emergiu como um instrumento técnico-científico de dominação e controle sobre a natureza dos homens (Luz, 1988). As verdades cartesianas se fundam em pressupostos que buscavam a essência das coisas fora delas, a partir de cál culos e de medidas, seguindo uma lógica formal, baseada no método cartesiano (D escartes, 1999).

$\mathrm{Na}$ concepção espinosiana, a essência das coisas está na existência delas. Não há como separar corpo ealma ou corpo e ambiente, por exemplo. Diferente da concepção cartesiana que acreditava em duas substâncias diferentes, a do corpo e a da mente (Descartes, 1991b), segundo Espinosa todas as coisas são constituídas por uma só substância e tomam formas diferentes em seus modos de existência. A idéia de univocidade espinosiana é que somos todos (diferencialmente) iguais numa origem imanente, a substância, e somos diferentes porque somos, cada um, um modo único de ser da substância (M artins, 1997; 1999; 2000). Assim um ser humano é um ser uno e múltiplo ao mesmo tempo. Na realidade éa substância que nos une, mas em modos diferentes de existir.

Tanto a razão quanto as sensações são constituídas da mesma substância. Racional é o que corresponde à realidade de modo formal como, por exemplo, a matemática e as leis da física. A razão é uma etapa no conhecimento, que pode ser ultrapassada na busca de uma dimensão humana do conhecimento, que conjuga razão e afetos, na vivência da racionalidade. Nos termos espinosianos, o humano não corresponde a um ideal, a uma idealização ou projeção, e, portanto, não é passível de escala, uma vez que não há um critério transcendente ou transcendental para medir "graus" de humanidade. Nestes termos, não somos mais ou menos humanos, assim como também o ser humano não vem se tornando evolutivamente mais humano.

Compreender requer, observa Espinosa, ser afetado de diversos modos (...), [e assim] éútil ao homem; e é-lhe tanto mais útil, (...) ser afetado de mais maneiras ou a afetar os outros corpos. E pelo contrário, é Ihe prejudicial aquilo que torna o corpo menos apto para isto (Espinosa, 1992). Nesse sentido, é numa conduta ética que nos aproximamos da realidade complexa. A ética a que estamos nos referindo é da ordem do singular, que não se submete a valores externos como o certo e o errado, ou como o bem e o mal, que nada mais são do que modos de imaginar, nos quais a imaginação é afetada diversamente (Espinosa, 1992). 0 bem no sentido ético não é uma qualidade física ou metafísica, nem uma espécie de ente à parte: 0 bem é apenas o esforço para perseverar no ser (Carvalho, 1992).

U ma conduta ética se dá na existência; é a conduta humana diante da vida, e representa a busca de uma forma de estarmos ativos no mundo. A Ética éa confirmação plena da corre lação, senão da subordinação, do pensamento puramente teórico à finalidade prática (CarvaIho, 1992). Assim, uma concepção ética articula teoria e prática e implica uma reflexão sobre nossas ações de forma que nos seja possível viver um máximo de momentos ativos e criativos, com um máximo do que Espinosa chama de afetos alegres. A conduta ética parte do conhecimento, da capacidade de sermos causa eficiente de nossa própria força de ação, e não sermos causa de outros (alienus), ou seguir passivamente causas externas. Sermos os causadores, os responsáveis por uma ação que surge na singularidade, não implica desobediência de regras, pois estas são necessárias à nossa vida, mas implica não deixar que outros ou as regras, isoladamente, determinem nossas ações.

Conhecer para Espinosa é o caminho para aumentar nossa potência de agir, saber mais sobre nós e estarmos mais ativos e criativos. $\mathrm{N}$ ão conhecer nossas causas internas nos distancia de nosso impulso espontâneo para perseverar na existência, do movimento intrínseco a nós (conatus), e nos coloca numa posição vulnerável, numa submissão às causas externas, diminuindo nossa potência de agir, nos tornando passivos. A atividade está ligada à potência. Já a passividade nos leva à servidão, quando, sem conhecimento de nós mesmos, não percebemos que as causas internas foram substituídas pelas externas. Sem conseguirmos reconhecer, no poderio externo, aquele que nos domina, ficamos refém de outrem, escravos sem saber que o somos. Estaríamos assim reagindo, alienados de nós, passivos, sem usar nossa capacidade ativa e criativa, o que diminui 
nossa potência e nos impulsiona a um círculo vicioso de dependência, muitas vezes, dependência daquele ou daquilo que nos domina. A marca da servidão élevar o apetite desejo à forma limite: a carência insaciável que busca interminavelmente a satisfação fora de si, num outro que só existe imaginariamente. (...) A servidão (...) do lado do indivíduo, (...) coloca-o em contradição consigo mesmo, levando- 0 a confundir interior e exterior, perdendo a referência de seu conatus e, justamente por isso provocando a própria destruição (...), do lado da vida intersubje tiva, torna cada um contrário a todos os outros, em luta contra todos os outros, temendo e odiando todos os outros, cada qual imaginando satisfazer seu desejo com a destruição do outro, percebido como obstáculo aos apetites e desejos de cada um e de todos os outros (Chauí, 2000).

0 conhecimento, que associa a razão à vivência, constitui um caminho para a liberdade. Não podemos ser totalmente livres, mas podemos ser otimamente livres se estivermos mais ativos na vida. Seremos mais livres quanto mais compreendermos nossas necessidades singulares quando se apresentam na vida, na corporeidade, atravessadas inevitavel mente pelas regras de cada época. Esse conhecimento tende a aumentar nossa potência de agir. No Tratado político (1979b), Espinosa escreve que (...) nada do que atesta impotência no homem pode se relacionar com a sua liberdade. Q uanto mais consideramos que um homem élivre, menos podemos dizer que ele não pode usar da razão e preferir o mal a um bem. Nesse sentido a liberdade não é um livre-arbítrio nosso em relação às leis divinas ou à natureza, ou ao nosso próprio corpo, não é uma questão de "comer ou não comer a maçã do conhecimento". Em primeiro lugar, a liberdade não se confunde com um poder voluntário para escolher entre alternativas, ou para fazer ou deixar de fazer alguma coisa; em segundo, se a impotência não pode ter a potência da liberdade como causa, então não podemos atribuir a esta 0 pecado original ou a culpa originária do homem (Chauí, 2000).

Quanto mais intuitivamente cientes das causas que nos afetam, mais poderemos estar ativos; quanto menos cientes delas, mais estaremos ao sabor do acaso no ambiente em que vivemos (um mar de acasos). A racionalidade espinosiana se aproxima da complexidade na vivência da razão, que pode aumentar nossa potência na realidade, aumentar a possibilidade de estarmos ativos e de estarmos mais livres no mundo.

\section{A obesidade e a conduta ética no conflito}

Segundo o modelo cartesiano, a obesidade é hoje geralmente tratada segundo uma mecânica, como se o corpo fosse uma máquina de entrada e saída de energia, e como se a "vontade" da pessoa gorda, seu "livre-arbítrio", devesse moralmente determinar sua adesão à dieta prescrita. Segundo a dicotomia entre corpo e mente, a mente ditaria ao corpo o que este deve fazer, cabendo a esta parte da pessoa, sua res extensa, portanto, submeter-se à sua outra parte, res cogitans, usando para isso sua força de vontade, disciplina e arbítrio. Caso o obeso não siga a dieta, estaria como que no lugar do pecado, na servidão da alma perante a compulsividade do corpo. Em nenhum momento, neste modelo, a pessoa é vista como una, vivenciando uma dissociação e um conflito de fatores simbólicos, muitas vezes contraditórios e paradoxais, cuja complexidade não se reduz a uma luta dicotômica entre corpo e razão.

Este conflito, no entanto, pode representar um movimento de vida capaz de aumentar a potência de agir. Um embate comum na realidade do corpo gordo - comer porque gosta, ou não comer porque engorda - é capaz de se agravar com a normalização nutricional, na forma racionalizada de uma ingestão recomendada, se esta não se articular com a realização pessoal do indivíduo em questão. Tanto uma normalização nutricional como uma realização pessoal, isoladas uma da outra, escamoteiam a interação real do corpo com o ambiente em que vive. As recomendações de ingestão diária de nutrientes representam uma alimentação saudável se e somente se possi bilitam transformações, inerentes à sua corporeidade, em prol do aumento de sua potência de agir.

Em outras palavras, além de conhecer a razão da norma, é preciso conhecer a si mesmo para que, conhecendo as próprias necessidades, o indivíduo possa adaptar as regras à sua existência sem corromper-se ou criar exigências impossíveis de serem vivenciadas de forma potente e saudável. U ma relação ética entre alimentação, corpo e saúde deve tornar as regras nutricionais flexíveis às necessidades da corporeidade singular, uma adaptação que se dá na realidade com a compreensão das vivências do indivíduo, com o devido conhecimento e reflexão sobre seus conflitos internos e ambivalências. Há neste embate uma adaptação das regras, que se propõem a manter um corpo em boas condições de funcionamento mas que 
nem sempre coincidem com a necessidade da corporei dade. Uma obediência rígida às recomendações nutricionais certamente restringiria as possibilidades de integrar o conhecimento racional à realidade complexa do indivíduo, e reforçaria o mito de que a problemática da obesidade se resolve simplesmente na elaboração de uma dieta que cumpra as recomendações nutricionais.

A nutrição moderna racionalizou as dietas na necessidade urgente de salvar vidas e garantir braços fortes para o trabalho (Rosen, 1994). A fome no mundo excede os limites da compreensão, constituindo um estado de emergência. No entanto, para elaborar políticas de alimentação é preciso compreender que a relação entre alimentação, saúde e corpo vai além da capacidade que 0 alimento tem de fornecer energia e nutrientes, e vai além do direito constitucional que temos ao alimento nosso de cada dia. A alimentação possui também um significado vital de fraternidade e confiança no ambiente em que vivemos. 0 sufocamento desse aspecto vitalizador do alimento é o que pretendemos evitar quando aplicamos os princípios éticos no aparente impasse "comer porque quero ou não comer porque engorda". Uma conduta ética pode sustentar, em um sistema nutricional racionalizado, a abertura de um espaço para a imprevisibilidade da vida. Um espaço de acoIhimento da tensão gerada na contraposição do prazer de alimentar-se e a obediência às recomendações nutricionais. Esse conflito pode positivamente envolver o início desordenado de uma nova reapropriação criativa do ambiente. Já a interdição, ao contrário, pode adoecer um corpo, pois pode representar um impedimento da expansão do movimento intrínseco do sujeito, o conatus, causando uma diminuição de sua potência de agir, na forma da culpa, da depressão, da angústia, no sentimento de que se está aquém de um ideal não só de corpo como também de conduta e de força de vontade.

As normas nutricionais, culturalmente impostas, quando agregadas à pessoa como causas externas fragmentam-na, enfraquecendo-a. Se as regras impostas nas determinações nutricionais não se constituírem eticamente, não promoverão a expansão de seu movimento e assim não promoverão corpos potentes e ativos, mas corpos obedientes e passivos. Numa conduta ética, o desafio da nutrição é a transformação das regras racionais, concebidas genericamente, num bem para aquele corpo singular, daquela pessoa singular em seus aspectos fisiológicos e psíquicos, tanto objetiva quanto subjetivamente. Daí a importância em se conhecer aquele corpo bio-psicossocial na realidade, pois regras nutricionais quando isoladas da vida serão impotentes em si. Quando as causas são internas, quando o indivíduo participa da determinação de sua dieta singularizada, constituída sem idealizações, geram um sentimento de aprovação da vida, uma aceitação dos problemas como ponto de partida para uma transformação real. Na ambivalência do comer ou não comer, estar ativo implica uma decisão em prol de uma realização, seja ela comer ou não comer, com ciência que a vida traz em si inevitavelmente prazer e desprazer. Uma decisão sau dável envolve o maior prazer e o menor desprazer, dentro da realidade atual da pessoa.

\section{Fronteiras conceituais da obesidade}

Assumir que um indivíduo está saudável não é o mesmo que dizer que ele é normal. Com a construção de padrões de normalidade, a medicina assumiu a definição de saúde como uma normalidade, e a de doença, como uma anormalidade, estabelecendo com a fisiologia uma polaridade entre o normal e o patológico, na qual o indivíduo é ou não normal de acordo com um padrão ideal de saúde (Canguilhem, 1995). Como observa Elias (1994), grande parte do que chamamos de razões de "moralidade" ou "moral" preenche as mesmas funções que as razões "higiene" ou "higiênicas" para condicionar as crianças a aceitar determinado padrão social. A modelagem por esses meios objetiva a tornar automático o comportamento socialmente desejável, uma questão de autocontrole, fazendo com que o mesmo pareça à mente do indi víduo resultar de seu livre-arbítrio e ser de interesse de sua própria saúde ou dignidadehumana.

A medicina tem se baseado muito mais em padrões universais de idealização do ser humano do que na condição humana de vida dos corpos na sua relação com um ambiente particular. Segundo Foucault (1998), a medicina simula uma pseudo inovação na qual o pensamento contemporâneo, acreditando ter escapado a ele [ao positivismo] desde o final do século 19, nada mais fez do que redescobrir, pouco a pouco, o que o tornara possível. Na realidade, doença alguma está isolada no sujeito, mas é dependente do ambiente.

Uma normalização dos corpos é construída na racionalidade médica de acordo com um 
padrão universal de corpo humano instituído como o melhor para a espécie. Um padrão, porém, não é o corpo na realidade, mas uma reprodução deste num suposto outro corpo universalmente idealizado, onde o universal passa a servir de parâmetro de julgamento da essência dos particulares, podendo passar assim a desqualificá-los em sua existência presente, que, no entanto, éa única realidade concreta (...) [e] o faz na forma de mistificação, crença, ideologia e poder em nome de uma "verdade" transcendente ao real imanente ( $M$ artins, 1999).

A medicina social surgiu ao traçar regras de comportamento impostas pelo policiamento médico; depois, com a medicina científica, a construção de um tipo de corpo ideal/normal, em condições experimentais, de laboratório, incutiu nos corpos uma forma de controle da vida (Rosen, 1980). Atualmente, o círculo de preceitos enormas é traçado com tanta nitidez em volta das pessoas, a censura ea pressão da vida social que Ihes modela os hábitos são tão fortes, que os jovens têm apenas uma alternativa: submeter-se ao padrão de comportamento exigido pela sociedade, ou ser excluídos da vida num "ambiente decente". A criança que não atinge o nível de controle das emoções exigido pela sociedade é considerada como "doente", "anormal", "criminosa" ou simplesmente "insuportável" (Elias, 1994).

Hoje podemos questionar essa construção de uma normalidade, pois na realidade, o corpo normal não é necessariamente o corpo saudável, mas um estado ideal dos órgãos segundo um padrão ideal de vida da espécie, que a medicina deseja estabelecer. Enquanto o conceito de normalidade designa tanto o estado habitual dos órgãos, quanto seu estado ideal, a normatividade, segundo uma conceituação canguilhe miana (1995), designa a auto-produção dos corpos na realidade complexa. A capacidade de um corpo para agir é também sua capacidade normativa, isto é, sua capacidade para criar normas interativas com o ambiente. Assim sendo, um indivíduo é doente não por ausência de norma, mas por dificuldade de variar as normas para perseverar o seu ser. 0 indivíduo doente segue normas também, mas normas pouco ou nada flexíveis, num corpo passivo e impotente para fazer variar suas próprias normas. $\mathrm{Na}$ impotência a pessoa se torna incapaz de variar suas normas quando se expõe ao ambiente.

No contexto atual, a obesidade recebe duas definições: uma como um estado desviante dos padrões de normalidade na cultura, e nesse sentido o corpo gordo é definido como algo anormal, porque difere da idéia de indivíduo normal construída em um contexto social onde se atribui normalidade a um modelo de corpo com uma silhueta magra e/ou musculosa; e outra, a obesidade pode ser compreendida como uma doença, se ela representa um fator gerador de impotência do corpo e reduz as possibilidades de vida de um indivíduo no ambiente que lhe é próprio.

Um corpo gordo, na realidade, pode estar num movimento saudável e aumentando sua potência de agir. Se por um lado o corpo gordo se desvia dos padrões vigentes de beleza, ele não se desvia, contudo, de sua própria natureza humana, de sentir e perceber 0 ambiente à sua volta, afetando-se com as impressões do mundo. É nesse sentido que uma classificação antropométrica não avalia a saúde nos corpos. Primeiramente pelo caráter estático e pontual da antropometria, que perde a percepção do movimento; e depois porque reduz o corpo ao visível e mensurável, ignorando o psíquico, 0 dinâmico, o vivencial, isto é, a condição efetiva daquele corpo com a vida e com as suas atividades e projetos. 0 corpo não é somente aquilo que se pode ver, e aquilo que se vênem sempre admite medidas. Segundo Santana (1997), José Gil define o espaço do corpo através de uma passagem: Espaço do corpo é isto: se você está imerso numa grande banheira tomando banho, cai uma aranha sobre a superfície da água perto de seus pés e você se arrepia! Aquela aranha não Ihe tocou, mas tocou. O ra, a cada instante, nesse instante vocêtem um espaço do corpo: o seu corpo vai além do corpo próprio, para além dos limites do seu corpo.

A saúde de um corpo se dá em sua relação com seu meio. Um ambiente competitivo, com al tas expectativas de adequação a um corpo modelar, pode criar muitos problemas de realização pessoal para uma pessoa. 0 corpo humano busca aproximações e afetos no espaço social que aumentem sua potência de agir. Embora 0 espaço social possa ser desfavorável à expressão e realização da singularidade das pessoas, impondo por exemplo o modelo magro de beleza, desfavorável ao corpo gordo, é, por outro lado, nesta realidade que aquele corpo existe, e portanto é, num certo sentido, neste espaço que o corpo pode estar ativo e potente. Entendido desta forma, o conflito passa a ser não mais entre diminuir a potência do corpo ao comer demais ou diminuir a potência do corpo ao não comer para adequar-se à causa externa do modelo magro, mas sim entre aumentar a 
potência do corpo ao comer menos ou aumentar a potência do corpo assumindo-se como tendo um corpo potente mesmo que gordo. 0 estetismo, no sentido que Ihe dá Maffesolli (1996), atravessa a corporeidade porque o sensível é irreprimível, embora, no caso do corpo gordo, o caráter sensível do corpo e da existência seja em geral marginalizado, como se fosse um privilégio dos corpos adaptados aos padrões; como se o pecado da existência na carne fosse um privilégio dos que não pecam pela gula. As emoções e sensações são um assentimento de vida, seja por um corpo gordo ou magro, enquanto o medo das aparências, ao contrário, constitui uma forma de desprezo ao mundo.

A estética dos corpos pode ser causa adequada e aumentar a potência de agir de um corpo, pois suscita uma diversidade de emoções, que constituem seu ambiente afetivo. 0 estetismo, no sentido que estamos utilizando, denuncia a moralização que torna os corpos - tanto os que se incluem no padrão quanto os que dele se excluem - impermeáveis às emoções, uma moralidade quelimita o gesto espontâneo ( $M$ artins, 2000). 0 desejo de reconhecimento pelo outro pode sim representar uma potencialidade capaz de criar uma possibilidade de realização na busca de afetos e de convivência com outras pessoas. É preciso afetar-se para estar ativo. Bloquear os afetos é também bloquear a percepção de nossas necessidades. Os diálogos que se dão, no que diz respeito à corporeidade, entre saúde, normalidade e estética são um modo de reconhecermos as múltiplas exigências de um corpo em sua afirmação no ambiente. A desenvoltura social e mesmo a sedução são construídas na relação corpórea com o ambiente, e guardam a imprevisibilidade característica do humano. Cada indivíduo tem um modo próprio de reagir às impressões e às agressões do ambiente, diferente em cada momento de sua vida. A corporeidade pode manter com o ambiente uma plasticidade que gere novas configurações e novas expressões na reapropriação que o ambiente oferece. A enfermidade representa o sufocamento ea impossibilidade de o corpo se reapropriar de seu ambiente, independentemente das medidas do corpo.

\section{A questão da obesidade: considerações finais}

A contemporaneidade traz novas exigências de transdisciplinaridade e de aproximação com a realidade complexa, na qual uma concepção dicotômica do corpo separado da mente se torna um obstáculo. 0 entendimento da obesidade como um excesso de gordura, que positivamente se localiza na metade material do corpo humano, tem se mostrado cada vez mais limitante no enfrentamento dessa problemática. Reduzir o problema a uma questão física restringe as possibilidades terapêuticas no campo da nutrição. A desconstrução de uma definição determinística de obesidade expressa na idéia de um balanço de energia positivo, e sua reconstrução no âmbito da complexidade podem contribuir para operacionalizar terapêuticas e políticas de nutrição na área da saúde sob um novo olhar.

A razão espinosiana pode contribuir nessa construção porque propõe uma forma de conhecimento racional que não se destaca do corpóreo, do vivencial e do sensível, nem tampouco dita verdades ao corpo, como ocorre no cartesianismo. É nesta racionalidade vivenciada que somos capazes de nos conhecermos sem idealizações. Esse conhecimento não se dá isolado das variáveis do mundo dos sentidos, nem distante da desorganização do real imanente. $\mathrm{N}$ ão compreendemos o corpo humano afastado dele, mas quando racionalizamos aquilo que vivenciamos. A corporeidade se constitui na cultura incorporando subjetividades e se atualizando nas transformações do mundo. 0 ambiente tem um papel decisivo na problemática da obesidade, na qual o corpo transforma e é transformado pelo ambiente a partir de sua existência. Conhecer, nesse sentido, representa uma possibilidade, por exemplo, de discernir entre as supostas necessi dades que são criadas e impostas pela mídia na venda de produtos e fetiches, e as necessidades singulares de cada indivíduo. Esse conhecimento, poderia dizer, no sentido ético, se constitui hoje como um instrumento capaz de denunciar os fetiches e os implantes que tentam anular a natureza humana singular, denunciando um aprisionamento do sujeito em ideais de saúde distanciados de um corpo singular efetivamente potente e portanto saudável a seu modo.

Assim, a construção de um conceito de obesidade demanda uma concepção ética da vida. Uma ética que não se separa da corporeidade, não implica nem uma justiça nos corpos nem uma justeza nas dietas, mas um conhecimento das causas que aumentam nossa potência de agir. Conhecê-las representa aumentar as possibilidades de estarmos ativos na vida. Não 
conhecer as causas internas que nos afetam nos coloca vulneráveis e submissos às causas dos outros e a padrões supostamente universais, 0 que diminui nossa potência de agir, nos tornando passivos diante da realidade. Essa passividade pode levar à servidão. Estaríamos assim escravos das dietas, na obediência de normas que não são as nossas, que não são fruto de nossa normatividade própria, de nossa atividade e criatividade na interação com o mundo. Quando seguimos obedecendo às normas externas a nós, nutrimos a crença de que a sati sfação está fora de nós, o que diminui nossa potência e nos enreda em um círculo de dependência. Na alienação de si, o controle social pode levar a corporei dade a vivenciar e alimentar contradições - comer ou não comer - e dissociações imaginárias.

Uma conduta ética é libertadora, pois a liberdade de um corpo não está em poder escoIher os alimentos, mas em aproximar as recomendações nutricionais às necessidades que desenvolvemos na relação com o ambiente. N esse sentido, o corpo não é livre quando come o que supostamente quer, mas é livre quando consegue, conhecendo suas necessidades, realizá-las e querê-las. I sto é, querer o que aumenta sua potência de agir. A necessi dade não existe nem só no corpo, nem só na mente, mas no corpo humano inteiro, na unidade somatopsíquica que somos. Entender a necessidade de um corpo humano como somente do corpo ou somente da mente é um caminho para a escravidão e para a reatividade.

Uma conduta ética não representa a substituição de um modelo de corpo magro por outro modelo gordo. A impotência de um corpo gordo não está no reconhecimento dos modelos padronizados de beleza, mas no desconhecimento das necessidades próprias de sua corporeidade singular. A necessidade em seguir um modelo ideal de corpo magro éjá uma reação a uma causa externa que diminui sua potência de agir.

O conflito entre comer (porque quero) ou não comer (porque engorda) representa uma tensão vivenciada por um corpo gordo, mas traz em si uma possibilidade de transformação. Exercitamos, na tensão existente entre as recomendações nutricionais modernas, impostas como um controle social, e a realização pessoal, a utilidade da ética. 0 conflito representa uma possibilidade de transformação; assim, entendemos que reprimir um conflito alimentar não é resolvêlo, e que a repressão pode ge- rar doenças. 0 corpo não decide pelo prazer ou pelo desprazer, mas por um máximo de prazer e um mínimo de desprazer. Deste modo, muitas vezes optar por não comer uma guloseima não é negar o prazer, mas optar pelo mínimo de desprazer.

Numa tentativa de aproximação com a realidade construímos duas definições para obesidade. Tanto uma como outra envolvem o corpo com 0 ambiente. A obesidade pode ser compreendida como uma doença, quando representa um fator gerador de impotência do corpo em relação ao ambiente que lhe é próprio. $\mathrm{Na}$ impotência, a pessoa fica passiva quando se expõe ao seu ambiente, diminuindo sua potência de agir. Nesse sentido, defendemos que mesmo um corpo gordo pode, na realidade, estar num movimento saudável, se não compromete sua potência de agir. Nessa concepção, uma classificação antropométrica isoladamente não é capaz de avaliar a saúde nos corpos, pois foraclui a interação do corpo com o ambiente. Por outro lado, a obesidade pode ser definida como um desvio do padrão vigente de normalidade, que se baseia em um modelo magro e musculoso de corpo. Um corpo gordo é definido como algo anormal em uma cultura contemporânea que institui um modelo de corpo magro como uma imagem ideal de corpo. A idéia de indivíduo normal está construída a partir de médias da espécie humana e do imaginário social, determinada em um contexto social em que nossa cultura atribui normalidade a um modelo idealizado social e culturalmente, com medidas antropométricas predeterminadas. Em relação ao modelo de corpo intitulado de normal, o corpo gordo se torna na verdade desviante. No entanto, se ele se desvia dos padrões de beleza, ele não se desvia, contudo, de sua própria natureza e é capaz de sentir e perceber 0 ambiente a sua volta, afetando-se com as impressões do mundo, e caso o faça de forma ativa e potente, seria, neste sentido, saudável.

Assim, defendemos o estetismo no sentido de um assentimento de vida. Embora o modelo magro de beleza seja desfavorável ao corpo gordo, é na realidade sensível do mundo que um corpo - magro ou gordo - pode estar ativo e potente. 0 mito do sucesso profissional e amoroso a partir de um modelo idealizado de beleza é desmistificado na vida real e singular de cada um, na realização efetiva de cada corpo. A estética dos corpos pode aumentar a potência de agir de um corpo, pois envolve 
emoções, sensações e sentimentos que constituem um ambiente afetivo real e não imaginário. A sensibilidade da corporeidade que se coloca no estetismo promove encontros entre as pessoas, compartilha afetos e celebra isso numa vida social ativa. 0 estetismo nessa perspectiva é amoral, pois permeia uma vivência cotidiana dos corpos, sendo assim contrário à marginalização que a sociedade e os padrões difundidos pela mídia impõem sobretudo ao corpo gordo, como se este fosse incapaz de emoções e sensações.

Conhecendo a nós mesmos, nossas necessidades, somos livres para buscar os ambientes e as formas mais ad equadas para realizá-las. Assim continuamos receptivos ao mundo, mas selecionamos os ambientes que nos afetam. $\mathrm{Na}$ realidade, tanto uma atitude otimista como pessimista no que diz respeito às transformações da corporeidade não são muito mais que perspectivas consoladoras, recalcadoras da realidade do corpo diante do poder da normalização e da padronização. A corporeidade mantém com 0 ambiente uma plasticidade que traz novas configurações e novas expressões somente quando há uma reapropriação do ambiente, um processamento singular do que 0 mundo nos traz.

U ma conduta ética deve levar em conta as singularidades e a participação dos envolvidos nas mudanças de um comportamento alimentar. No caso da terapêutica, tratar-se-á de elaborar um esquema alimentar que respeite as singularidades do indivíduo eque seja elaborado de forma conjunta, com sua participação. Uma dieta imposta cerceia a liberdade das pessoas, escravizando-as. Uma vez passivas, é compreensível que, ainda que inconscientemente, rejeitem a dieta que Ihes fora imposta. Ademais, a própria passividade já implica uma diminuição de sua potência de agir, constituindo-se, portanto, em uma forma de adoecimento - imperceptível aos procedimentos convencionais da nutrição que utilizam a antropometria como instrumento fundamental no tratamento da obesidade.

No caso do planejamento de políticas de alimentação, tratar-se-ia também de respeitar as singularidades, inclusive culturais e locais, e, a partir de estudos das vivências alimentares dos grupos, planejar ações futuras e estratégias de adaptação dessas vivências às recomendações nutricionais, de modo a aumentar a potência das pessoas tornando-as mais ativas em seu ambiente. Não é possível, por exemplo, considerarmos ético criar estratégias para normalizar a alimentação dos grupos de acordo com um padrão global de alimentos supostamente necessários, pois entendemos que um modelo de assistência nutricional também escravizaria e diminuiria as potencial idades da comunidade se não contar com uma participação ativa dos indivíduos e da cultura que a compõe. Por exemplo, a diversidade alimentar presente em cada região constitui um recurso nutricional que nem sempreé considerado pelos planejadores que privilegiam uma alimentação globalizada, muitas vezes por falta de informações nutricionais a respeito de frutas e hortaliças cultivadas e nativas da própria região. 0 mesmo podemos dizer de práticas e serviços. 0 que queremos frisar é que o planejamento em saúde precisa considerar os recursos nutricionais locais, assim como também novas práticas em saúde, conhecendo, nestes, suas potencialidades que, muitas vezes, já fazem parte da cultura alimentar da região e não devem ser pacificadas pela automatização e gene ralização de al guns programas em saúde.

0 conceito de obesidade que procuramos reconstruir nesse trabalho, assim como o enfoque conceitual utilizado para isto têm diante de si um vasto campo de aplicação na elaboração de terapêuticas particulares, mas também de práticas de saúde e políticas de alimentação para as comunidades, onde a recu peração da história da comunidade pode ser uma estratégia para propostas criativas, capaz de destacar as singularidades das populações no campo da alimentação. A racionalidade nesses termos espinosianos permite uma compreensão de problemas complexos, como a obesidade, de uma forma ética, que leve em conta ao mesmo tempo as recomendações nutricionais e a realidade dos indivíduos e populações.

A avaliação nutricional pode estabelecer novos parâmetros nutricionais baseando-se também na compreensão obtida a partir de uma conceituação da problemática, estendendo sua percepção do corpo humano para além da antropometria; por exemplo, no que diz respeito aos aspectos subjetivos de interpretação da normalidade / normatividade dos indivíduos. No caso específico da obesidade são variadas as possibilidades de prescrição dietética, mas que, se isoladas das questões ambientais concernentes à vida efetiva do indivíduo incluídos seus aspectos psíquicos e simbólicos -, tendem a se tornar fórmulas idealizadas e inócuas. A definição de conceitos operacionais 
promove ainda uma interdisciplinaridade nas equipes de saúde na medida em que facilita a comunicação entre as especialidades, atravessando a todas. A conceituação ultrapassa uma divisão dicotômica entre metodologia quantitativa e qualitativa que, num certo sentido, não se sustenta mais diante da assunção da realidade como complexa.

\section{Colaboradores}

A M artins trabalhou na discussão teórica e M C Carvalho, no levantamento e análise de dados, na redação e discussão teórica.

\section{Referências bibliográficas}

Canguilhem G 1995. 0 normal e o patológico. Ed. Forense Universitária, Rio de Janeiro.

Carvalho J 1992. Introdução, pp. 8-93. In B Espinosa. Ética. Ed. Relógio D'Água, Lisboa.

Chauí M 2000. Paixão, ação e liberdade em Espinosa. FoIha de S. Paulo, 20 (ago):17.

Deleuze G \& Gattari F 1991. 0 que éfilosofia? Ed. 34, Rio deJaneiro.

Descartes R 1999. 0 discurso do método. Ed. Martins Fontes, São Paulo.

Descartes R 1991a. M editações. Nova Cultural, São Paulo.

Descartes R 1991b. As paixões da alma. Ed. Nova Cultural, São Paulo.

Elias N 1994. 0 processo civilizador, uma história dos costumes. Ed. Jorge Zahar, Rio de Janeiro. vol. I ell.

Espinosa B 1979a. Pensamentos metafísicos, pp. 1-40. In Espinosa - vida e obra. Abril Cultural, São Paulo.

Espinosa B 1979b. Tratado político, pp. 303-366. In Espinosa - vida e obra. Abril Cultural, São Paulo.

Espinosa B 1992. Ética. Ed. Relógio D’Água, Lisboa.

Foucault M 1966. As palavras e as coisas. Ed. Portugália, Lisboa.

Foucault M 1972. Arqueologia do saber. Ed. Vozes, Petrópolis.

Foucault M 1982 M icrofísica do poder. Ed. Graal, Rio de Janeiro.

Foucault M 1998. O nascimento da clínica. Ed. Forense Universitária, Rio de Janeiro.

Luz M T 1988. Natural Racional e Social, Razão M édica e Racionalidade Científica M oderna. Ed. Campus, Rio deJaneiro.
M affesolli M 1996. No fundo das aparências. Ed. Vozes, Petrópolis.

Martins A 2000. Amor: ilusão ou realidade? Winnicott, Espinosa, psicanálise e filosofia. IX Encontro LatinoAmericano sobre o pensamento de D. W. Winnicott. SBPRJ, Rio de Janeiro.

Martins A 1999. Novos paradigmas e saúde. Physis Revista de Saúde Coletiva 9 (1):83-112.

$M$ artins A 1997. Univocidade e ontologia em Deleuze e em Espinosa. In J Vasconcellos \& EAR Fragoso (orgs) Deleuze: imagens de um filósofo da imanência. Ed. UEL, Londrina.

Monteiro C 2000. La transición epidemiológica en el Brasil. In J Bacallao \& M Pena. La obesidad en la pobreza: un nuevo reto para la salud pública. Organización Panamericana de la Salud. Washington, n. 576.

Monteiro CA, Conde WL \& Popkin BM 2001. Independent effects of income and education on the risk of obesity in the Brazilian adult population. The Journal of Nutrition. EUA, 3(131).

Rosen G 1980. Da polícia médica à medicina social: ensaios sobre a história da assistência médica. Ed. Graal, Rio de Janeiro.

Rosen G 1994. U ma história da saúde pública. HucitecAbrasco, São Paulo-Rio de Janeiro.

Santana D 1997. Entrevista com José Gil. Cadernos de subjetividade, N úcleo de Estudos e Pesquisas da Subjetividade. Programa de Estudos Pós-Graduados em Psicologia Clínica da PUC-SP 5 (2):253-266.

Artigo apresentado em 3/3/2004

Aprovado em 14/6/2004

Versão final apresentada em 15/7/2004 